\title{
Surface facet dependence of competing alloying mechanisms
}

Cite as: J. Chem. Phys. 153, 244702 (2020); https://doi.org/10.1063/5.0034520

Submitted: 21 October 2020 . Accepted: 03 December 2020 . Published Online: 23 December 2020

(iD) Yicheng Wang, (D) Konstantinos G. Papanikolaou, Ryan T. Hannagan, Dipna A. Patel, Tedros A. Balema, Laura A. Cramer, Paul L. Kress, (Dichail Stamatakis, and (D. Charles H. Sykes

\section{COLLECTIONS}

Paper published as part of the special topic on Special Collection in Honor of Women in Chemical Physics and Physical ChemistryWCP2O20
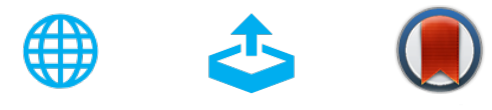

View Online

Export Citation

\section{ARTICLES YOU MAY BE INTERESTED IN}

Adsorption of methane on single metal atoms supported on graphene: Role of electron back-donation in binding and activation

The Journal of Chemical Physics 153, 244701 (2020); https://doi.org/10.1063/5.0035353

Machine learning with bond information for local structure optimizations in surface science The Journal of Chemical Physics 153, 234116 (2020); https://doi.org/10.1063/5.0033778

Probing the deformation of [12]cycloparaphenylene molecular nanohoops adsorbed on metal surfaces by tip-enhanced Raman spectroscopy

The Journal of Chemical Physics 153, 244201 (2020); https://doi.org/10.1063/5.0033383

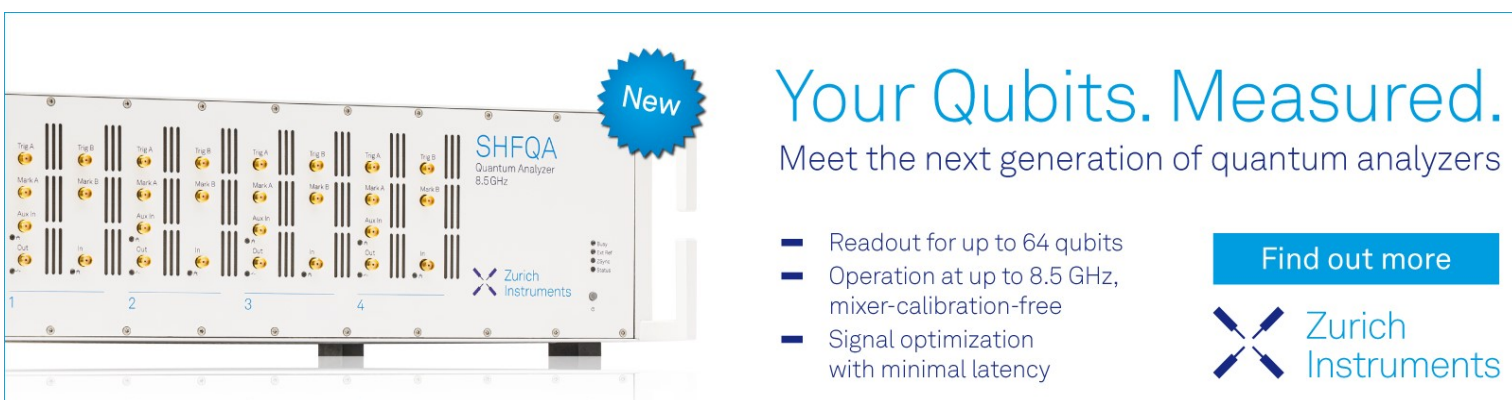




\title{
Surface facet dependence of competing alloying mechanisms
}

\author{
Cite as: J. Chem. Phys. 153, 244702 (2020); doi: 10.1063/5.0034520 \\ Submitted: 21 October 2020 - Accepted: 3 December 2020 • \\ Published Online: 23 December 2020
}

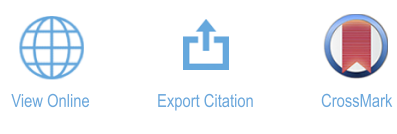

\author{
Yicheng Wang, ${ }^{1}$ (D) Konstantinos G. Papanikolaou, ${ }^{2}$ (D) Ryan T. Hannagan, ${ }^{1}$ Dipna A. Patel, ${ }^{1}$ Tedros A. Balema, \\ Laura A. Cramer, ${ }^{1}$ Paul L. Kress,' Michail Stamatakis, ${ }^{2, a)}$ (D) and E. Charles H. Sykes ${ }^{1, a)}$ (D)
}

\begin{abstract}
AFFILIATIONS
'Department of Chemistry, Tufts University, 62 Talbot Avenue, Medford, Massachusetts 02155, USA

${ }^{2}$ Thomas Young Centre and Department of Chemical Engineering, University College London, Roberts Building, Torrington Place, London WCIE 7JE, United Kingdom
\end{abstract}

Note: This paper is part of the JCP Special Collection in Honor of Women in Chemical Physics and Physical Chemistry.
a) Authors to whom correspondence should be addressed: m.stamatakis@ucl.ac.uk and charles.sykes@tufts.edu

\begin{abstract}
Metal alloys are ubiquitous in many branches of heterogeneous catalysis, and it is now fairly well established that the local atomic structure of an alloy can have a profound influence on its chemical reactivity. While these effects can be difficult to probe in nanoparticle catalysts, model studies using well defined single crystal surfaces alloyed with dopants enable these structure-function correlations to be drawn. The first step in this approach involves understanding the alloying mechanism and the type of ensembles formed. In this study, we examined the atomic structure of $\mathrm{RhCu}$ single-atom alloys formed on $\mathrm{Cu}(111), \mathrm{Cu}(100)$, and $\mathrm{Cu}(110)$ surfaces. Our results show a striking difference between $\mathrm{Rh}$ atoms alloying in $\mathrm{Cu}(111)$ vs the more open $\mathrm{Cu}(100)$ and $\mathrm{Cu}(110)$ surface facets. Unlike $\mathrm{Cu}(111)$ on which $\mathrm{Rh}$ atoms preferentially place-exchange with $\mathrm{Cu}$ atoms in the local regions above step edges leaving the majority of the $\mathrm{Cu}$ surface free of Rh, highly dispersed, homogeneous alloys are formed on the $\mathrm{Cu}(100)$ and (110) surfaces. These dramatically different alloying mechanisms are understood by quantifying the energetic barriers for atomic hopping, exchange, swapping, and vacancy filling events for $\mathrm{Rh}$ atoms on different $\mathrm{Cu}$ surfaces through theoretical calculations. Density functional theory results indicate that the observed differences in the alloying mechanism can be attributed to a faster hopping rate, relatively high atomic exchange barriers, and stronger binding of Rh atoms in the vicinity of step edges on $\mathrm{Cu}(111)$ compared to $\mathrm{Cu}(110)$ and $\mathrm{Cu}(100)$. These model systems will serve as useful platforms for examining structure sensitive chemistry on single-atom alloys.
\end{abstract}

Published under license by AIP Publishing. https://doi.org/10.1063/5.0034520

\section{INTRODUCTION}

Single-atom alloys (SAAs) are an emerging class of heterogeneous catalysts in which trace amounts of a reactive metal dopant exist in the form of isolated atoms in a less reactive but more selective host metal. ${ }^{1-16}$ The unique electronic and geometric properties of these SAA catalysts give rise to enhanced selectivity and stability for many reactions, deviations from "traditional" transition metal scaling relationships that limit catalyst performance, free-atom like d-states, and resistance to common catalyst poisons. ${ }^{7,13,17,18}$ As such, there has been widespread interest in these new materials in both the surface science and heterogeneous catalysis communities. However, the vast majority of the model system research has been conducted on (111) terminated surfaces, as (111) is the most commonly exposed facet of face-centered cubic (fcc) metal nanoparticles. To date, $\mathrm{PtCu}(111), \mathrm{PdCu}(111)$, $\mathrm{PdAu}(111), \operatorname{PtAg}(111), \mathrm{NiCu}(111), \mathrm{NiAu}(111), \mathrm{RhCu}(111)$, and PdAg(111) SAA model catalysts have been reported. ${ }^{1,19-25}$ Despite the thorough study of (111) terminated SAA surfaces, little research has been done on more under-coordinated (100) and (110) surfaces.

Structure sensitivity plays an important role in catalysis with the classic example of $\mathrm{NH}_{3}$ synthesis on body-centered cubic (bcc) $\mathrm{Fe}(111), \mathrm{Fe}(100)$, and $\mathrm{Fe}(110)$, where the more open/undercoordinated $\mathrm{Fe}(111)$ surface exhibits the highest dissociative $\mathrm{N}_{2}$ sticking coefficient and is responsible for the overall activity of the industrial catalyst. ${ }^{26,27}$ In terms of hydrocarbon chemistry, Jenks et al. examined the behavior of iodomethane 
and iodoethane on $\mathrm{Cu}(111), \mathrm{Cu}(100)$, and $\mathrm{Cu}(110)$ by using temperature-programmed desorption (TPD). Their results revealed that methylene coupling and $\beta$-hydride elimination are structure sensitive, while $\alpha$-hydride elimination is not. At high methyl iodide coverage, ethane desorption was $40 \mathrm{~K}$ lower for $\mathrm{Cu}(110)$ compared to $\mathrm{Cu}(100)$ and $\mathrm{Cu}(111)$, which represents approximately two orders of magnitude difference in the reaction rates. ${ }^{28}$ Specific to SAA catalysts, Gao et al. investigated higher alcohol synthesis on $\mathrm{RhCu}(111)$ and $\mathrm{RhCu}(100)$ SAA surfaces using Density Functional Theory (DFT). The energetic landscapes indicated that methanol formation is favored on $\mathrm{RhCu}(111)$, while ethanol may be the preferred product on $\mathrm{RhCu}(100){ }^{29}$ Jiang et al. experimentally studied the semihydrogenation of phenylacetylene on PdCu SAA nanosheets and nanocubes with predominantly (111) and (100) surfaces exposed, respectively. ${ }^{30}$ The authors concluded that while hydrogen spillover from the isolated $\mathrm{Pd}$ atoms to $\mathrm{Cu}$ occurred on both $\mathrm{Cu}$ surface facets, the $\mathrm{H}$ atoms that had spilled over were only active for phenylacetylene semi-hydrogenation on $\mathrm{Cu}(100)$. The lower barrier for the addition of the first $\mathrm{H}$ atom and the stronger phenylacetylene adsorption on $\mathrm{Cu}(100)$ vs $\mathrm{Cu}(111)$ were proposed as the reasons for the higher observed activity of the $\mathrm{PdCu}(100)$ based catalyst. However, such nanoparticle studies cannot completely rule out the contribution from minor exposed facets or adsorbate-induced reconstructions. Examining single crystals under ultrahigh vacuum (UHV), as we do in this paper, enables us to study the structure and alloying mechanism in well-defined facets with atomic-scale imaging resolution.

Theory work by Papanikolaou et al. has shown that SAA preparation is thermodynamically feasible on the (100) surface, as isolated dopant atoms have a positive aggregation energy, thereby remaining dispersed as isolated sites rather than agglomerating into dopant clusters. ${ }^{31}$ They also reported that the binding of $\mathrm{CO}$ is similar to SAAs formed on the (111) and (100) facets of $\mathrm{Cu}$. For instance, the $\mathrm{CO}$ binding energies for $\mathrm{RhCu}(111)$ and $\mathrm{RhCu}(100)$ are $-1.71 \mathrm{eV}$ and $-1.75 \mathrm{eV}$, respectively. Therefore, we may expect a similar reactivity on (100) and (111) surfaces, as the adsorption strength of small molecules often scales with reactivity. Modeling of $\mathrm{CO}_{2}, \mathrm{~N}_{2}$, and NO dissociation was conducted to probe the structure sensitivity of SAAs in $\mathrm{Cu}(100)$ and $\mathrm{Cu}(111)$ using DFT. These reactions exhibit similar structure sensitivity on SAAs and coinage metal surfaces, which is considerably less than platinum group metal (PGM) surfaces. For example, the dissociation barriers for $\mathrm{CO}_{2}$ on $\mathrm{RhCu}(100)$ and $\mathrm{RhCu}(111)$ are $0.74 \mathrm{eV}$ and $0.63 \mathrm{eV}$, respectively. This small degree of structure sensitivity can be attributed to slight differences in the electronic state of the $\mathrm{Rh}$ atom, which arise from the different coordination environments of Rh in the two surfaces. ${ }^{32}$ However, direct experimental evidence for SAA structure sensitivity on well-defined facets remains very limited. The first step toward elucidating the aforementioned effects involves the construction of SAA model catalysts on more open surfaces, and the key to that is a thorough understanding of alloy mechanisms of dopant atoms on these surface facets.

In this paper, we present a combined scanning tunneling microscopy (STM) and DFT study of the strikingly different alloying mechanisms of $\mathrm{Rh}$ in different facets of $\mathrm{Cu}$. We find that $\mathrm{Rh}$ forms dense brims on the $\mathrm{Cu}(111)$ surface, whereas in the more open (110) and (100) surfaces, Rh alloys uniformly across the terraces. Our calculations reveal that this occurs because of a delicate balance between diffusion and place-exchange barriers at different surface sites on the different surface facets. Overall, this work highlights the importance of the surface structure of the host material on alloying behavior, and these systems serve as well-defined model catalyst surfaces with which to interrogate the effect of structure sensitivity on SAA reactivity.

\section{EXPERIMENTAL METHODS}

\section{A. Low-temperature scanning tunneling microscopy (LT-STM)}

LT-STM experiments were conducted in UHV with a base pressure of $\sim 1 \times 10^{-11}$ mbar using an Omicron LT-STM. Sample cleaning was performed in the adjacent preparation chamber with the base pressure less than $2 \times 10^{-10}$ mbar. Repeated cycles of Ar (Airgas $99.99 \%$ ) ion bombardment and thermal annealing to $750 \mathrm{~K}$ were used for cleaning the $\mathrm{Cu}(111), \mathrm{Cu}(100)$, and $\mathrm{Cu}(110)$ single crystals. Rh deposition was performed with a Rh rod (Goodfellow 99.9\%) in a flux monitored by using an EFM 3 (Scienta Omicron) electron beam evaporator, while the $\mathrm{Cu}$ sample temperature was held at $380 \mathrm{~K}$ during deposition of a constant flux of $\sim 0.01 \mathrm{ML} \mathrm{min}^{-1}$. The STM images were acquired after cryogenically cooling the STM stage to $80 \mathrm{~K}$.

\section{B. Computational details}

DFT calculations were performed using the Vienna $a b$ initio simulation package (VASP). ${ }^{33,34}$ The electron-ion interactions were treated by the projector augmented method (PAW), ${ }^{35}$ and the wave functions of the valence electrons were expanded by plane waves with a kinetic energy cutoff of $400 \mathrm{eV}$. To describe the exchange and correlation effects, we employed the PerdewBurke-Ernzerhof (PBE) functional. ${ }^{36}$ Using this functional, we computed a lattice constant for $\mathrm{Cu}$ of $3.63 \AA$, which is in excellent agreement with the previous works and in reasonable agreement with the experimental value of $3.59 \AA \AA^{37}$ The electronic wave function was converged to $10^{-7} \mathrm{eV}$, and the Hellman-Feynman forces were relaxed to less than $10^{-2} \mathrm{eV} \AA^{-1}$. The low-index SAA $\mathrm{Rh} / \mathrm{Cu}(111), \mathrm{Rh} / \mathrm{Cu}(100), \mathrm{Rh} / \mathrm{Cu}(110)$, and $\mathrm{Rh} / \mathrm{Cu}(211)$ surfaces were modeled by a four-layer $\mathrm{p}(4 \times 4)$, a four-layer $\mathrm{p}(4 \times 4)$, an eight-layer $\mathrm{p}(4 \times 4)$, and a four-layer $\mathrm{p}(4 \times 1)$ cell, respectively (see Fig. S1 in the supplementary material). Some (110) surfaces, such as $\mathrm{Au}(110)$ and $\mathrm{Pt}(110)$, undergo a transition toward the energetically favored $(1 \times 2)$ missing row reconstruction geometry. ${ }^{38-40}$ $\mathrm{Cu}(110)$, however, is not known to be prone to such a reconstruction, and therefore, our DFT calculations focus on an ideal $(1 \times 1)$ geometry. ${ }^{41}$ The bottom two layers of the (111), (100), and (211) surfaces were fixed at the PBE-computed $\mathrm{Cu}$ lattice constant, while the top two layers and any $\mathrm{Rh}$ or $\mathrm{Cu}$ adatom thereon were allowed to relax during geometry optimization. For the (110) surface, the bottom four layers were fixed at the Cu lattice constant and the top four ones were allowed to relax. The following MonkhorstPack k-point meshes were used to sample the Brillouin zones of the considered surfaces: $4 \times 4 \times 1 \mathrm{k}$-point mesh for the (111) surface, 4 $\times 4 \times 1$ for the $(100)$ surface, $3 \times 4 \times 1$ for the $(110)$ surface, and $5 \times$ $4 \times 1$ for the (211) surface. ${ }^{42}$ Finally, transition states were identified 
with the dimer method, ${ }^{43}$ and vibrational analyses were performed in order to verify that each of the located transition states was a first order saddle point in the potential energy surface (PES). The adsorption energy of a $\mathrm{Rh}$ atom on a $\mathrm{Cu}$ surface and the reported activation barriers were calculated by the following equations:

$$
\begin{gathered}
E_{a d s}(\mathrm{Rh})=E_{\text {tot }}^{R h+\text { Slab }}-E_{\text {tot }}^{\text {Slab }}-E_{\text {tot }}^{R h_{(g)}}, \\
E_{a}=E_{T S}-E_{I S},
\end{gathered}
$$

where $E_{\text {tot }}^{R h+S l a b}, E_{\text {tot }}^{\text {Slab }}$, and $E_{\text {tot }}^{R h_{(g)}}$ are the total DFT energies for a $\mathrm{Cu}$ slab with a $\mathrm{Rh}$ adatom thereon, for a clean $\mathrm{Cu}$ slab, and for a $\mathrm{Rh}$ atom in the gas phase, respectively. $E_{T S}$ and $E_{I S}$ are the DFT-computed energies for the transition and initial states, respectively.

\section{RESULTS AND DISCUSSIONS}

\section{A. Scanning tunneling microscopy}

The $\mathrm{RhCu}$ alloys were prepared by depositing 0.01 monolayers (MLs) of $\mathrm{Rh}$ on $\mathrm{Cu}(111), \mathrm{Cu}(100)$, and $\mathrm{Cu}(110)$ single crystals at a substrate temperature of $380 \mathrm{~K}$. As shown in Fig. 1(a), the isolated $\mathrm{Rh}$ atoms appear as depressions in the $\mathrm{Cu}(111)$ surface. These $\mathrm{Rh}$ atoms are densely packed into the regions above step edges, suggesting a preferred alloying mechanism of Rh diffusion to step edges where place-exchange with $\mathrm{Cu}$ atoms in the upper terraces occurs, leading to the formation of an alloy brim above the step edges. This alloying mechanism has been observed for many other alloys formed by depositing dopant metals onto (111) surfaces. ${ }^{19,23,44}$ In sharp contrast to the (111) facet, our results on the $\mathrm{Cu}(110)$ and (100) facets [Figs. 1(b) and 1(c), respectively] reveal that under identical alloying conditions, unlike the (111) surface, Rh atoms are dispersed homogeneously in the $\mathrm{Cu}(100)$ and (110) terraces. Importantly, we did not observe any of the dense alloy brims in the regions above step edges for the RhCu alloys in the more open (100) and (110) surfaces. These results indicate that $\mathrm{Rh}$ can form SAAs on all three facets of
$\mathrm{Cu}$, in agreement with the previous DFT studies that have revealed an enthalpic preference of $\mathrm{Rh}$ atoms to exist as isolated species in $\mathrm{Cu}(111)$ and $\mathrm{Cu}(100)$ surfaces. ${ }^{17,3}$

The distribution of $\mathrm{Rh}$ atoms in the different $\mathrm{Cu}$ surface facets suggests that different alloying mechanisms are at play on $\mathrm{Cu}(111)$ vs $\mathrm{Cu}(100)$ and (110). Place-exchange at step edges appears to be favored for $\mathrm{RhCu}(111)$ vs exchange directly into the terraces for $\mathrm{RhCu}(100)$ and $\mathrm{RhCu}(110)$. While this agrees with the mechanisms previously discussed in the literature, there has never been a direct comparison of alloying the same element into different surface facets under identical alloying conditions.

\section{B. Theoretical investigations}

In order to elucidate the disparate alloying behavior exhibited by $\mathrm{RhCu}(111)$ and the other two low-index facets investigated (Fig. 1), we performed periodic DFT calculations. These calculations were aimed at elucidating the mechanism by which $\mathrm{Rh}$ is incorporated into the $\mathrm{Cu}$ host metal and also the mechanism by which $\mathrm{Rh}$ adatoms diffuse over the $\mathrm{Cu}(111), \mathrm{Cu}(100)$, and $\mathrm{Cu}(110)$ surfaces. In terms of the diffusion of Rh adatoms, one may simply assume that this process occurs via site-to-site hops, with the Rh adatom sliding over a corrugated plane. Indeed, this is the simplest and most intuitive diffusion mechanism. However, surface science and theoretical studies have demonstrated that adatom diffusion over single crystals can be far more complex than that, thereby highlighting that other types of diffusion, besides hopping, merit consideration. ${ }^{4-47}$ For example, using an atom probe, Wrigley and Ehrlich argued that the diffusion of a W adatom across the rows of $\operatorname{Ir}(110)$ occurs via a concerted atomic exchange mechanism. ${ }^{48}$ Under these circumstances, the $\mathrm{W}$ adatom, which is initially adsorbed on a hollow site, displaces a neighboring Ir atom from a row of the (110) surface, and the latter becomes the "new adatom." This atomic exchange mechanism has been observed and, often, corroborated as the dominant adatom diffusion mechanism in a number of field-ion microscopy
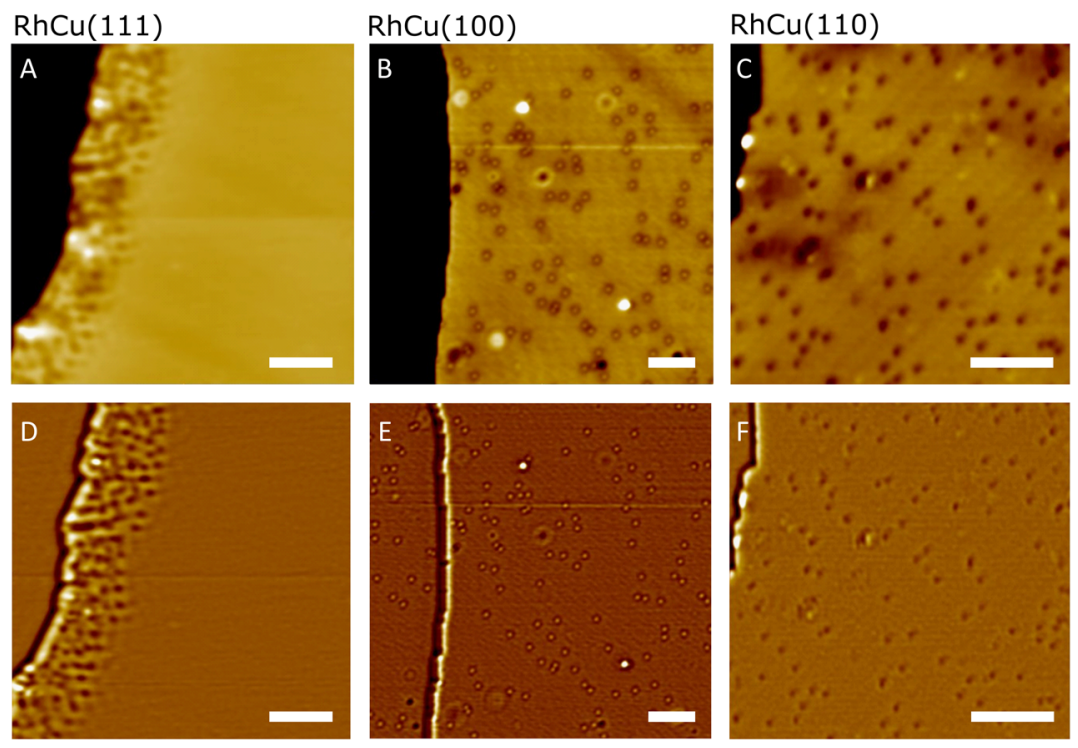

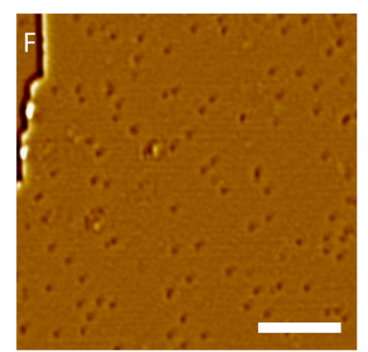

FIG. 1. STM images of $0.01 \mathrm{ML} \mathrm{RhCu}$ SAAs prepared in the (111), (110), and (100) facets of $\mathrm{Cu}$. (a) $\mathrm{RhCu}(111)$ in which dense brims of $\mathrm{Rh}$ appear in the regions above step edges and the $\mathrm{Rh}$ atoms appear as depressions. (b) $\mathrm{RhCu}(100)$ in which isolated $\mathrm{Rh}$ atoms can be seen alloyed throughout the terrace with no dense brims at the step edges. (c) $\mathrm{RhCu}(110)$ in which isolated $\mathrm{Rh}$ atoms are also seen alloyed throughout the terraces. (d)-(f) Derivative STM images corresponding to images (a)-(c) that highlight the Rh alloying sites in different Cu facets. Typical imaging conditions: $300 \mathrm{mV}$ and $300 \mathrm{pA}$. The scale bars are $5 \mathrm{~nm}$. All SAA surfaces were prepared via $\mathrm{Rh}$ deposition on $\mathrm{Cu}$ held at $380 \mathrm{~K}$, followed by cooling to $80 \mathrm{~K}$ for STM imaging. 
and theoretical studies, which focus on low-index facets with an open structure [e.g., (110), (100), and (001)]. ${ }^{49-54}$ Another possible diffusion mechanism is diffusion via an existing vacancy in the host material. This is the so-called vacancy-mediated exchange diffusion, ${ }^{55}$ which has been shown to be pronounced on more densely packed surfaces such as $\mathrm{Cu}(111)$.

With this in mind, we used DFT to study the following surface processes on $\mathrm{Cu}(111), \mathrm{Cu}(100)$, and $\mathrm{Cu}(110)$ surface facets: (i) hopping of a $\mathrm{Rh}$ adatom from site-to-site on the surface, (ii) atomic exchange between a $\mathrm{Rh}$ adatom and a $\mathrm{Cu}$ surface atom, (iii) integration of a $\mathrm{Rh}$ adatom into the $\mathrm{Cu}$ surface via a vacancy, and (iv) atomic swapping between $\mathrm{Rh}$ and $\mathrm{Cu}$ surface atoms (Fig. 2). $\mathrm{Rh}$ diffusion via hopping involves "jumps" of a $\mathrm{Rh}$ adatom from a hollow site to another hollow site via a twofold bridge site, which is the first order saddle point in the PES [Fig. 2(a)]. The hollow sites correspond to fourfold sites on $\mathrm{Cu}(110)$ and $\mathrm{Cu}(100)$ and threefold sites (either fcc or hcp) on $\mathrm{Cu}(111)$ [Fig. 2(a)]. Our results suggest that simple $\mathrm{Rh}$ adatom hopping is significantly more facile on the $\mathrm{Cu}(111)$ surface $\left(\mathrm{E}_{\mathrm{a}, \mathrm{fcc} \rightarrow \mathrm{hcp}}=0.23 \mathrm{eV}\right.$ or $\left.\mathrm{E}_{\mathrm{a}, \mathrm{hcp} \rightarrow \mathrm{fcc}}=0.06 \mathrm{eV}\right)$ than on $\mathrm{Cu}(100)\left(\mathrm{E}_{\mathrm{a},(100)}=0.90 \mathrm{eV}\right)$ and $\mathrm{Cu}(110)\left(\mathrm{E}_{\mathrm{a},(110)}=0.37 \mathrm{eV}\right)$.
(A)

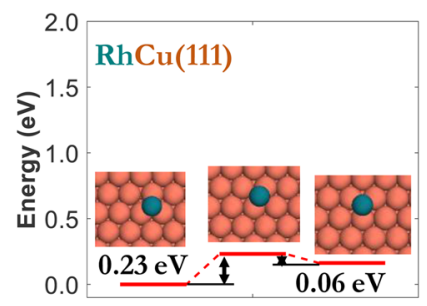

(B)

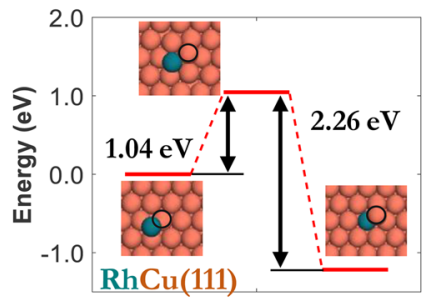

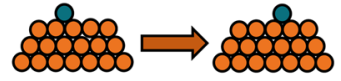
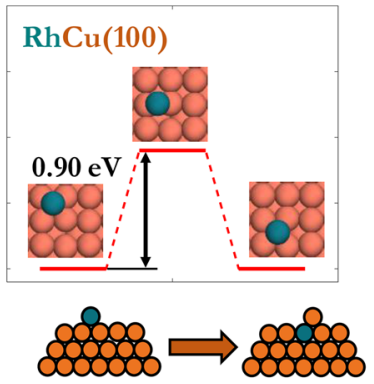

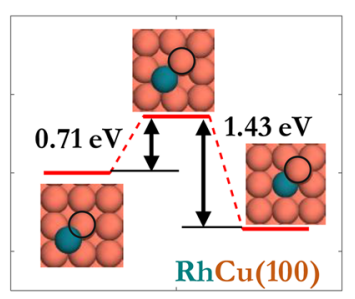

(Side view)

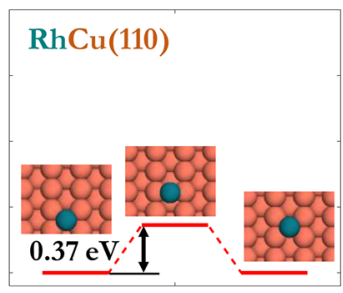

(Side view)

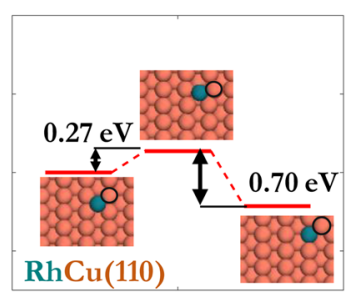

(Side view)

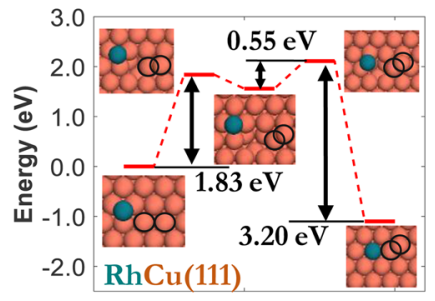

(D)

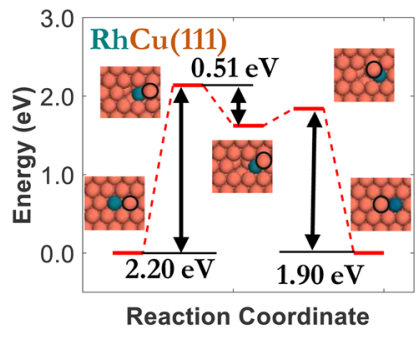

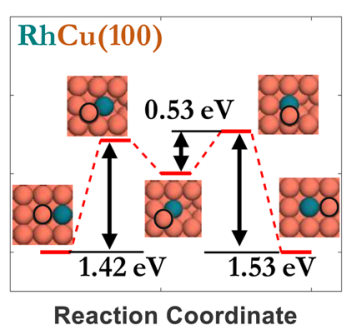

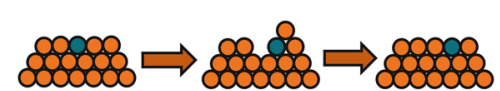

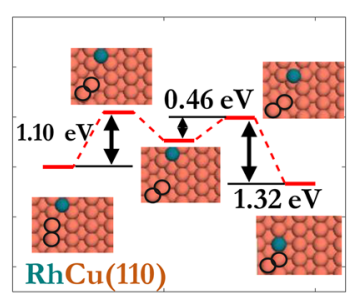

(Side view)

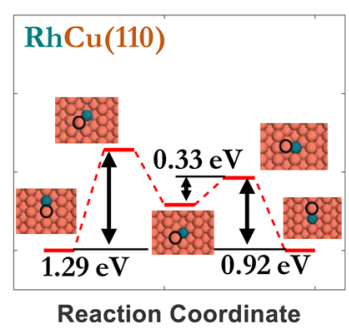

FIG. 2. DFT-computed kinetic barriers for (a) Rh hop diffusion, (b) atomic exchange, (c) Rh integration via a vacancy, and (d) atomic swapping for the three investigated low-index surfaces. A side view representation of the different alloying steps is given above each panel, where we only show states that correspond to a minimum in the PES. Cu and $\mathrm{Rh}$ atoms are shown in orange and teal, respectively. $\mathrm{Cu}$ atoms that participate in an event are annotated by black circles. 
The same trend has been reported for the self-diffusion of $\mathrm{Cu}$ over these three low-index surfaces by Hansen et al., ${ }^{56}$ and the fast adatom hopping over $\mathrm{Cu}(111)$ is in line with the work of Anderson et al. on a $\mathrm{PbCu}(111)$ system. ${ }^{55}$ Importantly, we note that the reported hopping barrier for $\mathrm{Cu}(110)$ in Fig. 2(a) involves $\mathrm{Rh}$ hopping along the rows of the $\mathrm{Cu}(110)$ surface. We have also computed the corresponding barrier for Rh hopping across these rows, and we have found a large kinetic barrier of $1.82 \mathrm{eV}$ (see Fig. S2 of the supplementary material). This high value implies that diffusion across the rows will be highly unlikely via hopping, in qualitative agreement with previous works.

Atomic diffusion on either pure metal or alloy surfaces often takes place via a concerted mechanism in which more than one atom participates in the diffusion event. ${ }^{47,57-59}$ To this end, we continue our investigations by computing the energy barriers for a concerted atomic exchange between a $\mathrm{Rh}$ adatom and a $\mathrm{Cu}$ atom [Fig. 2(b)]. The atomic exchange proceeds in a similar manner on the three $\mathrm{Cu}$ surfaces: the Rh adatom is initially adsorbed on a hollow site; in the transition state, a $\mathrm{Cu}$ atom is "lifted-up" by the adatom and a "Rh$\mathrm{Cu}$ dimer" is formed above a surface vacancy; and in the final state, $\mathrm{Rh}$ is integrated into the $\mathrm{Cu}$ host surface, while the lifted-up $\mathrm{Cu}$ atom ends up as an adatom over a mixed hollow site [Fig. 2(b)]. In contrast to the previously discussed hop diffusion [Fig. 2(a)], we find that atomic exchange events are much more easily activated on the open $\mathrm{Cu}(100)\left(\mathrm{E}_{\mathrm{a},(100)}=0.71 \mathrm{eV}\right)$ and $\mathrm{Cu}(110)\left(\mathrm{E}_{\mathrm{a},(110)}=0.27 \mathrm{eV}\right)$ surfaces as compared to $\mathrm{Cu}(111)$, where $\mathrm{E}_{\mathrm{a},(111)}=1.04 \mathrm{eV}$. Consequently, the computed barriers in Figs. 2(a) and 2(b) indicate that the predominant alloying mechanism toward the SAA phase will be different among the three low-index surfaces and begins to explain the observed disparate distribution of Rh atoms over these three surfaces (Fig. 1). In particular, our results in Figs. 2(a) and 2(b) demonstrate that $\mathrm{Rh}$ atoms that land on $\mathrm{Cu}(111)$ will be able to diffuse via hopping across the surface before they experience the appropriate alloying sites (e.g., step edges) that enables them to integrate into the $\mathrm{Cu}$ host surface. By contrast, $\mathrm{Rh}$ integration via direct atomic exchange into the terraces of the $\mathrm{Cu}$ host will be more favorable on $\mathrm{Cu}(100)$ and $\mathrm{Cu}(110)$ than hopping. This allows Rh adatoms to incorporate easily and directly in the terraces and, therefore, form a uniform and well-dispersed SAA phase over the whole single crystal surface (Fig. 1).

Another mechanism by which $\mathrm{Rh}$ can be incorporated into the host material is via an existing vacancy on the $\mathrm{Cu}$ host surface [Fig. 2(c)]. To investigate this type of mechanism, we first computed the energy cost for the creation of a vacancy on the $\mathrm{Cu}$ crystal [Figs. 2(c) and 3(a)] and then the energy cost for the filling of this vacancy by a $\mathrm{Rh}$ adatom. The computed vacancy formation barriers are $1.83 \mathrm{eV}$ for $\mathrm{Cu}(111), 1.31 \mathrm{eV}$ for $\mathrm{Cu}(100)$, and $1.10 \mathrm{eV}$ for $\mathrm{Cu}(110)[$ Fig. 2(c)]. According to this result, the more open a surface is, the higher its tendency to form a vacancy. Moreover, we calculated the vacancy formation barrier on the edge of a (211) step [see Fig. 3(b)], which serves as a model of the region around step edges of the $\mathrm{Cu}$ crystals seen in Fig. 1. The computed vacancy formation barrier at this site, for a clean $\mathrm{Cu}(211)$ surface in the absence of a $\mathrm{Rh}$ adatom, is $1.38 \mathrm{eV}$.

It is noteworthy that the kinetic barrier for vacancy filling [i.e., the second barrier from left to right in the PES of Fig. 2(c)] is $1.10 \mathrm{eV}$ for $\mathrm{Cu}(100)$ and $0.46 \mathrm{eV}$ for $\mathrm{Cu}(110)$. These values are $\sim 0.40 \mathrm{eV}$ and $0.20 \mathrm{eV}$ larger than the corresponding atomic exchange barriers, respectively, and merely reflect the difficulty of Rh hop diffusion over these $\mathrm{Cu}$ surface facets [Fig. 2(a)]. Consequently, the incorporation of $\mathrm{Rh}$ on these surfaces will be more probable via an atomic exchange mechanism even in the presence of vacancies on the host material. In contrast, the vacancy filling barrier on $\mathrm{Cu}(111)\left(\mathrm{E}_{\mathrm{a},(111)}=0.55 \mathrm{eV}\right)$ is almost half of the corresponding atomic exchange barrier $\left[\mathrm{E}_{\mathrm{a},(111)}=1.04 \mathrm{eV}\right]$. Therefore, we conjecture that the high concentration of Rh atoms in the vicinity of step edges of $\mathrm{Cu}(111)$ (see Fig. 1) may be explained by the following four factors: (i) the fast $\mathrm{Rh}$ adatom hopping on $\mathrm{Cu}(111)$ [Fig. 2(a)], (ii) the higher susceptibility of the region near the step toward the formation of vacancies as compared to the densely packed (111) plane [Fig. 3(a)], (iii) the relatively easy integration of a Rh adatom into an existing vacancy on the $\mathrm{Cu}(111)$ surface [Fig. 2(c)], and (iv) the high stability of a $\mathrm{Rh}$ atom embedded in the $\mathrm{Cu}(111)$ host surface [see the first inset in Figs. 2(b) and 2(c)].

Furthermore, the significantly stronger binding of $\mathrm{Rh}$ in the vicinity of step edges as compared to the threefold sites of $\mathrm{Cu}(111)$ $\left[E(\mathrm{Rh})_{a d s,(211)}-E(\mathrm{Rh})_{a d s,(111)}=-0.96 \mathrm{eV}\right]$ will be the driving force for $\mathrm{Rh}$ migration to the step edges of $\mathrm{Cu}(111)$ after deposition [Fig. 3(a)]. This migration is expected to occur through simple and fast hop diffusion. Accordingly, the incorporation of Rh adatoms on $\mathrm{Cu}(111)$ will probably occur via the existing or created vacancies, which are more likely to form in the vicinity of the step edges [Fig. 3(a)]. This will lead to a kinetically trapped state, whereby the majority of $\mathrm{Rh}$ atoms are incorporated in the region above the step edge (Fig. 1). ${ }^{19,23-25,44}$ Depending on the conditions, the system could remain trapped in this metastable state for a considerable amount of time, ${ }^{55}$ before reaching equilibrium - namely, a state where entropy will be the driving force toward a well-dispersed SAA phase. ${ }^{8,17,18,23-25,31,44,60}$ In contrast, on $\mathrm{Cu}(100)$, the atomic exchange events exhibit a relatively small barrier of $0.71 \mathrm{eV}$, and given the fact that an embedded $\mathrm{Rh}$ atom in the $\mathrm{Cu}$ host surface exhibits high stability [see Fig. 2(b)], we speculate that the integration of Rh adatoms into the $\mathrm{Cu}(100)$ surface will occur at or near their "point of landing," thereby leading to the formation of a uniformly dispersed SAA surface as seen in Fig. 1.

The last type of surface event we studied involves the atomic swapping of an embedded $\mathrm{Rh}$ atom and a Cu surface atom [Fig. 2(d)] that leads to the diffusion of the $\mathrm{Rh}$ atom in the $\mathrm{Cu}$ surface. We find that atomic swapping is not a concerted event (i.e., the initial and final states are not separated by just one transition state) but rather occurs in two steps. The first step involves the displacement of a $\mathrm{Cu}$ atom out of the $\mathrm{Cu}$ host surface by a neighboring $\mathrm{Rh}$ atom; in the second step, the displaced $\mathrm{Cu}$ "diffuses back" and fills the created vacancy [Fig. 2(d)]. Our calculations reveal a very large barrier for the first step on $\mathrm{RhCu}(111)\left(\mathrm{E}_{\mathrm{a},(111)}=2.20 \mathrm{eV}\right)$, while the corresponding kinetic barriers for the first step on $\mathrm{RhCu}(100)$ and $\mathrm{RhCu}(110)$ surfaces are moderate $\left[\mathrm{E}_{\mathrm{a},(100)}=1.42 \mathrm{eV}\right.$ and $\mathrm{E}_{\mathrm{a},(110)}$ $=1.29 \mathrm{eV}$ ] [Fig. 2(d)]. In this way, atomic swapping and atomic exchange between an embedded $\mathrm{Rh}$ atom and a $\mathrm{Cu}$ adatom will be equally likely events on $\mathrm{RhCu}(100)$, but they will be activated at relatively high temperatures $\left(\mathrm{E}_{\mathrm{a}}>1.40 \mathrm{eV}\right.$ for both events) [see Figs. 2(b) and $2(\mathrm{~d})$ ]. In contrast, our results predict that the dominant diffusion event for $\mathrm{RhCu}(110)$ will be the atomic exchange [Figs. 2(b) and $2(\mathrm{~d})]$.

Finally, we elucidated the distinctive alloying behavior of the three surfaces further by calculating the approximate rates of the 
(A)

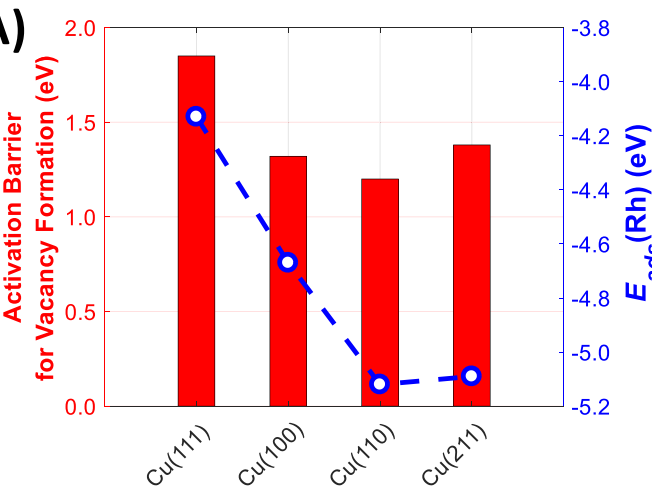

(B)

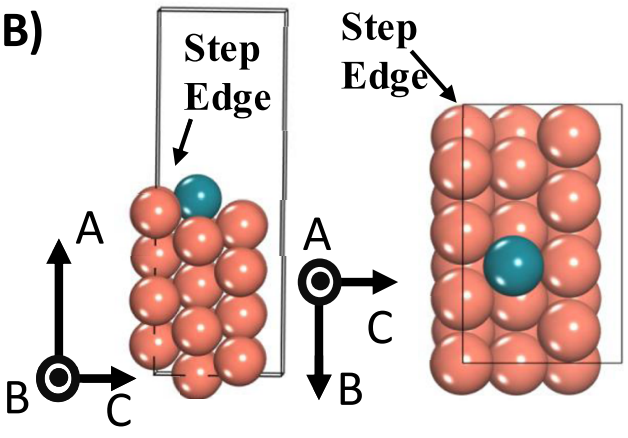

(C)

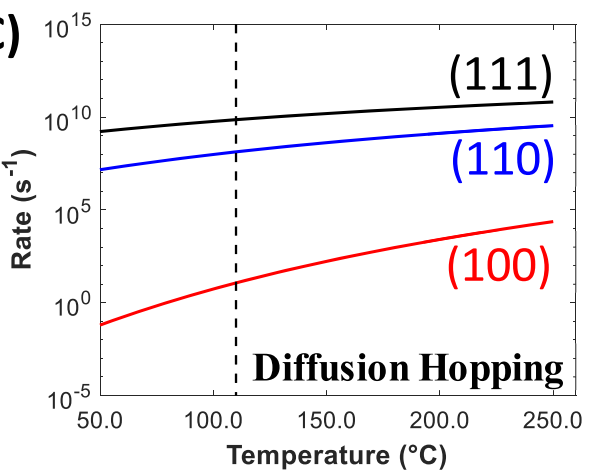

(D)

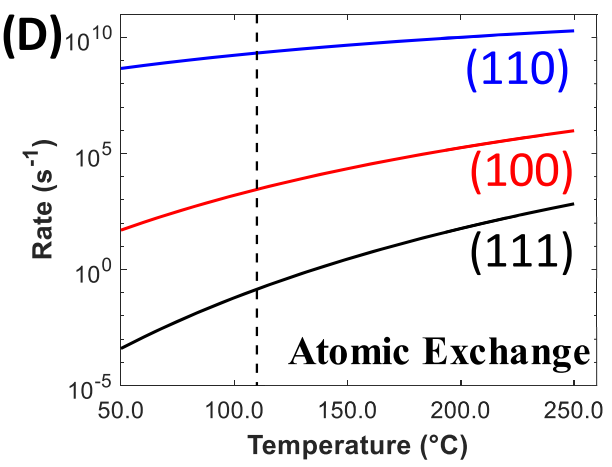

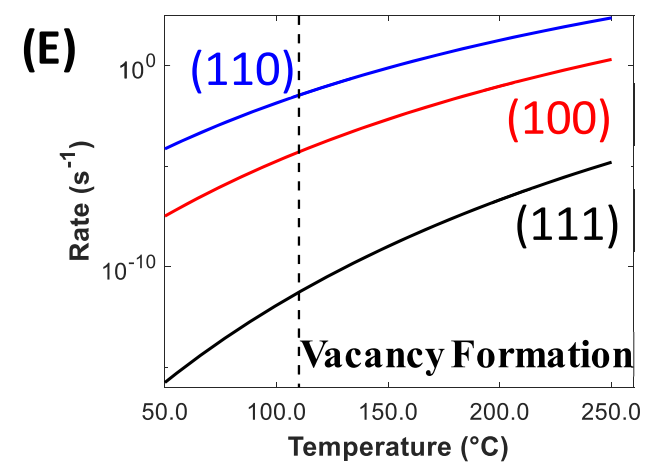

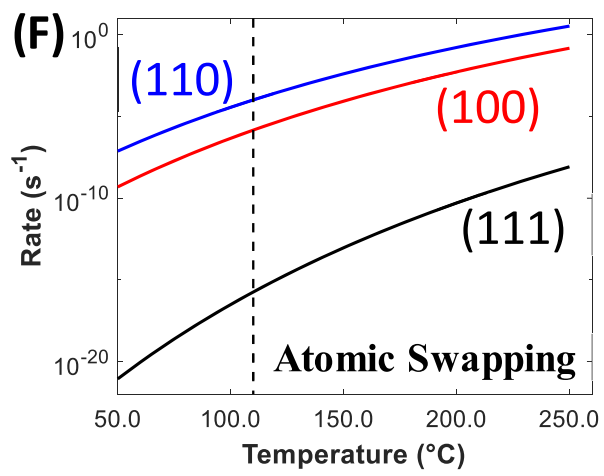

FIG. 3. Energy cost for vacancy formation on pure Cu surfaces and adsorption energies of a Rh adatom on the most stable adsorption site of the same surfaces. The reported barriers in panel (a) refer to clean Cu surfaces in the absence of a Rh adatom. The most stable adsorption site for Rh is a fcc site for $\mathrm{Cu}(111)$ and a fourfold site for $\mathrm{Cu}(100)$ or $\mathrm{Cu}(110)$. (b) The most stable adsorption site for a Rh adatom (teal) on the (211) surface. (c)-(f) Computed rates for Rh hop diffusion, atomic exchange, vacancy formation (in the presence of a Rh adatom in the close vicinity to the vacancy), and atomic swapping, respectively. The dashed line is always at $110^{\circ} \mathrm{C}$, which is the temperature at which alloying was performed in our experiments.

different surface processes. According to the computed kinetic barriers and by using the Eyring equation ${ }^{61}$ with a prefactor of $\mathrm{k}_{B} \mathrm{~T} / \mathrm{h}$ ( $\mathrm{k}_{\mathrm{B}}$ and $\mathrm{h}$ are Boltzmann's and Planck's constants, respectively), we computed the approximate rates for the investigated processes within the temperature range of $50{ }^{\circ} \mathrm{C}-250^{\circ} \mathrm{C}$ [Figs. 3(c)-3(f)]. Since $\mathrm{Rh}$ incorporation and atomic swapping are not elementary processes, the reported rates are those for their first steps, which exhibit the largest kinetic barriers. Our principal observation is that atomic exchange, vacancy formation, and atomic swapping are faster on $\mathrm{Cu}(100)$ and $\mathrm{Cu}(110)$ than on $\mathrm{Cu}(111)$ by at least five orders of magnitude at $110^{\circ} \mathrm{C}$ [Figs. $3(\mathrm{c})-3(\mathrm{f})$ ], while the opposite holds true for hop based diffusion. This observation further clarifies the disparate behavior of the three facets in relation to the diffusion and incorporation of $\mathrm{Rh}$ atoms and suggests that indeed the integration of Rh will occur via different mechanisms on the three surface facets. 


\section{CONCLUSIONS}

We have examined and directly compared the alloying behavior of small amounts of $\mathrm{Rh}$ with $\mathrm{Cu}(111), \mathrm{Cu}(100)$, and $\mathrm{Cu}(110)$ surface facets using STM. In agreement with the previously published results on $\mathrm{Cu}(111)$, we observed that most of the Rh atoms are found in dense brims of the isolated sites above step edges. In stark contrast, on the $\mathrm{Cu}(100)$ and (110) surfaces, we found that $\mathrm{Rh}$ atoms alloy directly into the terrace of $\mathrm{Cu}(100)$ and $\mathrm{Cu}(110)$ surfaces. This result suggested that the direct exchange of $\mathrm{Rh}$ with $\mathrm{Cu}$ atoms in terraces is favored on more open surfaces. DFT calculations were used to quantify the relevant energetics behind these striking differences in alloying behavior. We found that the lowest hopping diffusion barrier for $\mathrm{Rh}$ atoms occurs on the $\mathrm{Cu}(111)$ facet, while atomic exchange is favored over diffusion on $\mathrm{Cu}(100)$ and $\mathrm{Cu}(110)$ facets. The vacancy filling mechanism was then investigated by examining the activation barrier for vacancy formation and vacancy filling. Vacancy formation on $\mathrm{Cu}(211)$ was studied as well to simulate the step edges on $\mathrm{Cu}(111)$ where alloying occurs. These results indicated that the vacancy formation barrier is comparable among the $\mathrm{Cu}(211), \mathrm{Cu}(100)$, and $\mathrm{Cu}(110)$ surfaces and much lower than the corresponding barrier on $\mathrm{Cu}(111)$. Furthermore, the stronger binding of $\mathrm{Rh}$ atoms to $\mathrm{Cu}$ sites in the vicinity of step edges acts as a driving force for Rh migration to these sites on $\mathrm{Cu}(111)$. Furthermore, the approximate rates for the aforementioned processes were computed in the temperature range of $50{ }^{\circ} \mathrm{C}-250^{\circ} \mathrm{C}$. The results indicate that atomic exchange, vacancy formation, and atomic swapping occur much faster on $\mathrm{Cu}(100)$ and $\mathrm{Cu}(110)$, while atomic hopping is much faster on $\mathrm{Cu}(111)$. These predictions that $\mathrm{Rh}$ atoms tend to become kinetically trapped in the regions above step edges on $\mathrm{Cu}(111)$, while atomic exchange and swapping tend to occur on $\mathrm{Cu}(100)$ and $\mathrm{Cu}(110)$, rationalize our experimental STM results that show a high dispersion of $\mathrm{Rh}$ in $\mathrm{Cu}(100)$ and (110) vs a preference for the formation of dense alloy regions above step edges on $\mathrm{Cu}(111)$. Together, our synergistic experimental-theoretical approach demonstrates and explains the different alloying mechanisms in the three most common facets of $\mathrm{Cu}$ and paves the way for a direct cross-comparison of reactivity and the elucidation of structure sensitivity in SAA catalysis.

\section{SUPPLEMENTARY MATERIAL}

See the supplementary material for details of the $\mathrm{Cu}$ slabs used in the DFT calculations.

\section{AUTHORS' CONTRIBUTIONS} work.

Y.W., K.G.P., M.S., and E.C.H.S. contributed equally to this

\section{DEDICATION}

This manuscript is dedicated to my former graduate students Professor Ashleigh Baber, Professor Erin Iski, Dr. Heather Tierney, Dr. April Jewell, Dr. Emily Lewis, and Dr. Felicia Lucci. Their hard work and enthusiasm were instrumental in the establishment of the Sykes research group. I owe them a debt of gratitude for their devotion to science and for their continued mentoring of the next generation of scientists.

\section{ACKNOWLEDGMENTS}

The experimental work at Tufts was supported by the U.S. Department of Energy and by the Division of Chemical Sciences, Office of Basic Energy Science, CPIMS Program, under Grant No. DE-SC 0004738. K.G.P. was funded by the Department of Chemical Engineering, University College London. The authors acknowledge the use of the UCL High Performance Computing Facilities Kathleen@UCL in the completion of the simulations of this work.

\section{DATA AVAILABILITY}

The data that support the findings of this study are available from the corresponding authors upon reasonable request.

\section{REFERENCES}

${ }^{1}$ G. Kyriakou, M. B. Boucher, A. D. Jewell, E. A. Lewis, T. J. Lawton, A. E. Baber, H. L. Tierney, M. Flytzani-Stephanopoulos, and E. C. H. Sykes, Science 335, 1209 (2012).

${ }^{2}$ F. R. Lucci, J. Liu, M. D. Marcinkowski, M. Yang, L. F. Allard, M. Flytzani-Stephanopoulos, and E. C. H. Sykes, Nat. Commun. 6, 8550 (2015).

${ }^{3}$ G. Sun, Z. J. Zhao, R. Mu, S. Zha, L. Li, S. Chen, K. Zang, J. Luo, Z. Li, S. C. Purdy, A. J. Kropf, J. T. Miller, L. Zeng, and J. Gong, Nat. Commun. 9, 4454 (2018).

${ }^{4}$ F. Xing, J. Jeon, T. Toyao, K.-I. Shimizu, and S. Furukawa, Chem. Sci. 10, 8292 (2019).

${ }^{\mathbf{5}}$ M. Luneau, T. Shirman, A. C. Foucher, K. Duanmu, D. M. A. Verbart, P. Sautet, E. A. Stach, J. Aizenberg, R. J. Madix, and C. M. Friend, ACS Catal. 10, 441 (2020). ${ }^{6}$ H. Li, K. Shin, and G. Henkelman, J. Chem. Phys. 149, 174705 (2018).

${ }^{7}$ M. T. Darby, R. Réocreux, E. C. H. Sykes, A. Michaelides, and M. Stamatakis, ACS Catal. 8, 5038 (2018).

${ }^{8}$ K. K. Rao, Q. K. Do, K. Pham, D. Maiti, and L. C. Grabow, Top. Catal. 63, 728 (2020).

${ }^{9}$ J. Liu, F. R. Lucci, M. Yang, S. Lee, M. D. Marcinkowski, A. J. Therrien, C. T. Williams, E. C. H. Sykes, and M. Flytzani-Stephanopoulos, J. Am. Chem. Soc. 138, 6396 (2016).

${ }^{10}$ M. B. Boucher, B. Zugic, G. Cladaras, J. Kammert, M. D. Marcinkowski, T. J. Lawton, E. C. H. Sykes, and M. Flytzani-Stephanopoulos, Phys. Chem. Chem. Phys. 15, 12187 (2013).

${ }^{11}$ M. D. Marcinkowski, M. T. Darby, J. Liu, J. M. Wimble, F. R. Lucci, S. Lee, A. Michaelides, M. Flytzani-Stephanopoulos, M. Stamatakis, and E. C. H. Sykes, Nat. Chem. 10, 325 (2018).

${ }^{12}$ M. D. Marcinkowski, A. D. Jewell, M. Stamatakis, M. B. Boucher, E. A. Lewis, C. J. Murphy, G. Kyriakou, and E. C. H. Sykes, Nat. Mater. 12, 523 (2013).

${ }^{13}$ M. T. Greiner, T. E. Jones, S. Beeg, L. Zwiener, M. Scherzer, F. Girgsdies, S. Piccinin, M. Armbrüster, A. Knop-Gericke, and R. Schlögl, Nat. Chem. 10, 1008 (2018).

${ }^{14}$ B. Seemala, C. M. Cai, C. E. Wyman, and P. Christopher, ACS Catal. 7, 4070 (2017).

${ }^{15}$ L. Zhou, J. M. P. Martirez, J. Finzel, C. Zhang, D. F. Swearer, S. Tian, H. Robatjazi, M. Lou, L. Dong, L. Henderson, P. Christopher, E. A. Carter, P. Nordlander, and N. J. Halas, Nat. Energy 5, 61 (2020).

${ }^{16}$ G. X. Pei, X. Y. Liu, X. Yang, L. Zhang, A. Wang, L. Li, H. Wang, X. Wang, and T. Zhang, ACS Catal. 7, 1491 (2017).

${ }^{17}$ M. T. Darby, E. C. H. Sykes, A. Michaelides, and M. Stamatakis, Top. Catal. 61, 428 (2018).

${ }^{18}$ R. T. Hannagan, G. Giannakakis, M. Flytzani-Stephanopoulos, and E. C. H. Sykes, Chem. Rev. 120, 12044 (2020). 
${ }^{19}$ F. R. Lucci, T. J. Lawton, A. Pronschinske, and E. C. H. Sykes, J. Phys. Chem. C 118, 3015 (2014).

${ }^{20}$ J. Liu, M. B. Uhlman, M. M. Montemore, A. Trimpalis, G. Giannakakis, J. Shan, S. Cao, R. T. Hannagan, E. C. H. Sykes, and M. Flytzani-Stephanopoulos, ACS Catal. 9, 8757 (2019).

${ }^{21}$ Z.-T. Wang, M. T. Darby, A. J. Therrien, M. El-Soda, A. Michaelides, M. Stamatakis, and E. C. H. Sykes, J. Phys. Chem. C 120, 13574 (2016).

${ }^{22}$ M. Muir and M. Trenary, J. Phys. Chem. C 124, 14722 (2020).

${ }^{23}$ D. A. Patel, P. L. Kress, L. A. Cramer, A. M. Larson, and E. C. H. Sykes, J. Chem. Phys. 151, 164705 (2019).

${ }^{24}$ D. A. Patel, R. T. Hannagan, P. L. Kress, A. C. Schilling, V. Çınar, and E. C. H. Sykes, J. Phys. Chem. C 123, 28142 (2019).

${ }^{25}$ R. T. Hannagan, D. A. Patel, L. A. Cramer, A. C. Schilling, P. T. P. Ryan, A. M. Larson, V. Çınar, Y. Wang, T. A. Balema, and E. C. H. Sykes, ChemCatChem 12, 488 (2019).

${ }^{26}$ F. Bozso, G. Ertl, and M. Weiss, J. Catal. 50, 519 (1977).

${ }^{27}$ G. Ertl, Angew. Chem., Int. Ed. 47, 3524 (2008).

${ }^{28}$ C. J. Jenks, B. E. Bent, N. Bernstein, and F. Zaera, J. Phys. Chem. B 104, 3008 (2002).

${ }^{29}$ Y. Gao, L. Shi, S. Li, and Q. Ren, Phys. Chem. Chem. Phys. 22, 5070 (2020).

${ }^{30}$ L. Jiang, K. Liu, S. Hung, L. Zhou, R. Qin, Q. Zhang, P. Liu, L. Gu, H. M. Chen, G. Fu, and N. Zheng, Nat. Nanotechnol. 15, 848 (2020).

${ }^{31}$ K. G. Papanikolaou, M. T. Darby, and M. Stamatakis, J. Phys. Chem. C 123, 9128 (2019)

${ }^{32}$ K. G. Papanikolaou and M. Stamatakis, Catal. Sci. Technol. 10, 5815 (2020).

${ }^{33}$ G. Kresse and J. Hafner, Phys. Rev. B 47, 558 (1993).

${ }^{34}$ G. Kresse and J. Furthmüller, Comput. Mater. Sci. 6, 15 (1996).

${ }^{35}$ P. E. Blöchl, Phys. Rev. B 50, 17953 (1994).

${ }^{36}$ J. P. Perdew, K. Burke, and M. Ernzerhof, Phys. Rev. Lett. 77, 3865 (1996).

${ }^{37}$ P. Haas, F. Tran, and P. Blaha, Phys. Rev. B 79, 085104 (2009).

${ }^{38}$ K.-M. Ho and K. P. Bohnen, Phys. Rev. Lett. 59, 1833 (1987).
${ }^{39}$ E. C. Sowa, M. A. Van Hove, and D. L. Adams, Surf. Sci. 199, 174 (1988).

${ }^{40}$ I. Matrane, M. Mazroui, R. Ferrando, M. Badawi, and S. Lebègue, Surf. Sci. 690, 121463 (2019).

${ }^{41}$ J.-M. Zhang, H.-Y. Li, and K.-W. Xu, Surf. Interface Anal. 39, 660 (2007).

${ }^{42}$ J. D. Pack and H. J. Monkhorst, Phys. Rev. B 16, 1748 (1977).

${ }^{43}$ G. Henkelman and H. Jónsson, J. Chem. Phys. 111, 7010 (1999).

${ }^{44}$ M. T. Darby, M. Stamatakis, A. Michaelides, and E. C. H. Sykes, "Lonely atoms with special gifts: Breaking linear scaling relationships in heterogeneous catalysis with single-atom alloys," J. Phys. Chem. Lett. 9, 5636-5646 (2018).

${ }^{45}$ F. Montalenti and R. Ferrando, Phys. Rev. B 59, 5881 (1999).

${ }^{46} \mathrm{H}$. Jónsson, Annu. Rev. Phys. Chem. 51, 623 (2000).

${ }^{47}$ M. Villarba and H. Jónsson, Phys. Rev. B 49, 2208 (1994).

${ }^{48}$ J. D. Wrigley and G. Ehrlich, Phys. Rev. Lett. 44, 661 (1980).

${ }^{49}$ B. D. Yu and M. Scheffler, Phys. Rev. B 56, R15569 (1997).

${ }^{50}$ P. J. Feibelman and R. Stumpf, Phys. Rev. B 59, 5892 (1999).

${ }^{51}$ R. T. Tung and W. R. Graham, Surf. Sci. 97, 73 (1980).

${ }^{52}$ P. Wynblatt and N. A. Gjostein, Surf. Sci. 12, 109 (1968).

${ }^{53}$ P. J. Feibelman, Phys. Rev. Lett. 65, 729 (1990).

${ }^{54}$ D. W. Bassett and P. R. Webber, Surf. Sci. 70, 520 (1978).

${ }^{55}$ M. L. Anderson, M. J. D’Amato, P. J. Feibelman, and B. S. Swartzentruber, Phys. Rev. Lett. 90, 126102 (2003).

${ }^{56}$ L. Hansen, P. Stoltze, K. W. Jacobsen, and J. K. Nørskov, Phys. Rev. B 44, 6523 (1991).

${ }^{57}$ H. Y. Kim and G. Henkelman, ACS Catal. 3, 2541 (2013).

${ }^{58}$ B. P. Uberuaga, G. Henkelman, H. Jónsson, S. T. Dunham, W. Windl, and R. Stumpf, Phys. Status Solidi B 233, 24 (2002).

${ }^{59}$ H. Wang, M. Stamatakis, D. A. Hansgen, S. Caratzoulas, and D. G. Vlachos, J. Chem. Phys. 133, 224503 (2010).

${ }^{60}$ K. G. Papanikolaou, M. T. Darby, and M. Stamatakis, ACS Catal. 10, 1224 (2020).

${ }^{61}$ H. Eyring, J. Chem. Phys. 3, 107 (1935). 